\title{
The cultural constitution of cognition: taking the anthropological perspective
}

\section{Andrea Bender* and Sieghard Beller}

Department of Psychology, Albert-Ludwigs-University, Freiburg, Germany

\section{Edited by:}

Ulrike Hahn, Cardiff University, UK

Reviewed by:

Todd M. Gureckis, New York University, USA

Disa Sauter, Max-Planck Institute for Psycholinguistics, Netherlands Olivier Le Guen, Max-Planck Institute for Psycholinguistics, Netherlands

\section{${ }^{*}$ Correspondence:}

Andrea Bender, Department of

Psychology, Albert-Ludwigs-University,

Engelbergerstr. 41, D-79085 Freiburg,

Germany.

e-mail: bender@psychologie.

uni-freiburg.de
To what extent is cognition affected by culture? And how might cognitive science profit from an intensified collaboration with anthropology in exploring this issue? In order to answer these questions, we will first give a brief description of different perspectives on cognition, one that prevails in most cognitive sciences - particularly in cognitive psychology - and one in anthropology. Three basic assumptions of cognitive science regarding the separability of content and process, the context-independence of processing, and the culture-independence of processing will then be discussed. We argue that these assumptions need to be questioned and scrutinized cross-culturally. A thorough examination of these issues would profit considerably from collaboration with anthropologists, not only by enabling deeper insight into the cultures under scrutiny, but also by synergistic effects that would allow for a more comprehensive understanding of human cognition.

Keywords: cognitive science, anthropology, cognition, culture, interdisciplinarity

\section{INTRODUCTION}

Perspective taking is a capability that we all learn as infants, at least in principle (e.g., Baillargeon et al., 2010), and yet even as adults, we still have our difficulties accomplishing it (Galinsky et al., 2006; Wu and Keysar, 2007): In our attempts to find orientation in the outside world, in social relations and interactions, or in our inner life, we often presume that we are adopting the only possible perspective, and hence find it difficult to view things from a different angle. In this regard, cognitive scientists barely differ from anybody else. For good reasons (in fact, better reasons than most other people) they assume to understand cognitive processes, and for similar good reasons, they believe to have achieved this insight by well-suited methods.

This picture changes somewhat, when turning to non-familiar cultures. When visiting a far-away country, most of us are hit by realizing that the people we meet show opinions, values, and behaviors that do not at all match our expectations. Suddenly, we have no difficulties imagining - and might even find it inevitable - that "the others" will perceive and most likely reason about the world differently from us. But how great are these differences really, and on which level do they arise? When we are in contact with "exotic" cultures, do we overestimate that, which we tend to underestimate in daily life? Or does what (and maybe even how) we perceive, think, and feel actually depend on the culture in which we grew up? In this regard, a substantial proportion of cognitive scientists seem to differ considerably from anybody else by assuming that cognition is largely independent from culture. Whereas anthropologists and ethnolinguists explore the specific cultural context and content of cognition, cognitive psychologists and psycholinguists prefer to work on what they assume to be universal aspects of cognition.

More importantly, these two groups tend to ignore each other's perspectives of the subject they both work on. Research on human cognition has all too often ignored cultural diversity, and anthropology has all too often remained mute to discussions in cognitive science. As a consequence, research in cognitive science may fall prey to certain biases even in their approach to research questions and design (e.g., White, 2006). In this paper, we aim at elaborating the advantages of taking different perspectives, and we do so in at least two different senses: taking a cross-cultural perspective on cognition, and taking a cross-disciplinary perspective in cognitive research. Although we hope to contribute to a more general discussion in the cognitive sciences, we will basically focus on the value of anthropology for questions of cognitive psychology, as these are the two disciplines we are most familiar with ${ }^{1}$. We argue that combining these perspectives will give rise to synergistic effects and will allow for a more comprehensive understanding of human cognition - one that includes its cultural constitution.

\section{PERSPECTIVES ON COGNITION}

The opinion that cognitions are constituted by vs. independent of culture mark two endpoints between which not only lay-psychology explanations, but also scientific perspectives on cognition, seem to have oscillated over the last decades.

While during colonialism, Europeans increasingly came into contact with people from other cultures, one leading school in the social sciences assumed that "the natives" differ in principle from people in "modern Western civilizations" in how they reason. Lévy-Bruhl (1910, 1922), for instance, defined this "primitive mentality" as a

${ }^{1}$ This is not to say that other disciplines are less relevant for cognitive sciences or could not profit from increased cross-disciplinary collaboration. As one of the reviewers correctly stated, linguistics might play a bridge-building role in this regard. In fact, in the interaction of culture and cognition, language plays a specific, dual role: as a cognitive capacity/activity and as an essential part of culture. It is thus not by accident that much of the work perceived as being cognitive anthropology is actually done by ethnolinguists (e.g., Lucy, 1992a,b; Goody, 1995; Levinson, 2003; Enfield, 2004; Enfield and Levinson, 2006; Levinson and Wilkins, 2006). 
mystic-prelogic mode of thinking that largely consists of religious and supernatural elements. It was therefore impossible to describe this mode of thinking with logic-based rules or to make it compatible with the Cartesian mode of thinking, which he believed to be characteristic of Europeans. In his later years, Lévy-Bruhl partially withdrew this position. However, a modified version, according to which two modes of thinking are still distinguished-sometimes termed as rule-based vs. associative, reflective vs. intuitive, or abstract vs. content-specific - yet assumed to co-exist in all cultures, is still discussed in research on thinking and reasoning, albeit controversially (e.g., Sloman, 1996; Sperber, 1997; Beller and Spada, 2003; Evans, 2003; for a related discussion, see also Nisbett et al., 2001; Norenzayan et al., 2002; Nisbett, 2003).

The conception of the "psychic unity of humankind," in contrast, holds that, irrespective of their cultural background, all humans have at their disposal the same cognitive toolkit. Dating back at least to the Enlightenment, this position experienced a huge uplift in the 1950s and 1960s, when the cognitive revolution laid the foundation for a new field (Miller, 2003). Several disciplines - among them psychology and cultural anthropology - joined forces to explore the foundations of the human mind and its achievements (for overviews, see Gardner, 1985; Boden, 2006). Not only did they share a common goal, but they did so from a perspective that focused on mental states, which are generated and altered by way of information input, processing, storage, and transmission. According to a popular metaphor, information processing in a human mind is analogous to information processing that takes place in a computer, consists of algorithms and data and varies with regard to input and output, but not with regard to processing itself. We assume that it was this computer metaphor that gave rise to the following three basic-although often implicit - assumptions (see also Block, 1995; Norenzayan and Heine, 2005):

(1) Cognition can be split into processing and content (i.e., the information being processed).

(2) Cognition takes place in people's heads, which implies that processing is largely independent of context.

(3) Only content varies across cultures, whereas the processor itself, and hence the processing, are universal, that is, independent of people's cultural background.

For research on human cognition, these assumptions entail farreaching consequences. First, the assumed separability of process and content seemed to justify a division of labor according to which anthropology would account for the concrete cultural content of mental representations, and psychology would account for their cognitive processing (D'Andrade, 1981, p. 182). In recent years, though, this distinction turned out to be neither reasonable nor tenable (Medin and Atran, 2004; Bang et al., 2007), and not infrequently it has invited incorrect conclusions. This insight, however, should not have come as a surprise, if the computer metaphor had been taken more seriously. Computer science teaches us that the format of the data determines which algorithms can be performed smoothly and which cannot (e.g., Mehlhorn and Sanders, 2008), and so do specific formats of representing content affect the cognitive processes operating on them. A thorough examination of psychological processes must therefore always take content and its representation into account.
Second, the focus in early cognitive science on mental phenomena is comprehensible if one considers that it originated as countermovement to behaviorism (cf. Gardner, 1985). Whereas behaviorism categorically rejected the usability of mental constructs due to their inaccessibility for direct observation, the new discipline realized that behavior could only be accounted for if one understands what people are attending to and what information they are processing. For cognitive scientists and anthropologists alike this set the path: "We must get inside our subjects' heads" (Frake, 1964, p. 133).

The downside of this concentration on mental phenomena was a disregard for other factors with potential influence on cognitive processing. A range of cognitive activities are not exclusively performed internally, but rather in interaction with one's environment and with artifacts, which often serve precisely the purpose of facilitating cognitive processing (e.g., Norman, 1993). Instructive examples of this interaction are the usage of digits for calculations (Nickerson, 1988; Zhang and Norman, 1995) or of maps and technical instruments in navigation (Hutchins, 1995). For the incorporation of cognitive artifacts into cognitive processing, Hutchins (2006) coined the term "distributed cognition." Even beyond concrete tools, the context in which we process information may affect how we process it, particularly with regard to whether (and which) other people are present. One simple example of this effect is social facilitation (i.e., increasing individual performance on simple tasks when others are present), which has actually been known for at least a century (Bond and Titus, 1983; Guerin, 1993). To ensure their external validity, the common practice of examining cognitive processes under controlled conditions in labs is therefore rather critical.

Yet, this preference for controlled experiments on cognition has been reinforced by the third assumption, according to which cognitive processes are universal, that is, independent of people's cultural background. Support for this assumption even seemed to come from cognitive anthropology, which, in its early days, had found evidence for universal principles of organizing cognitive domains (e.g., Berlin et al., 1968; Berlin and Kay, 1969; Berlin, 1992). Hence, up to the end of the last century, the potential of culture to affect cognitive processes has been widely ignored (cf. Norenzayan and Heine, 2005; Bang et al., 2007; Henrich et al., 2010b), and this seemed to justify the widespread habit of exploring cognitive processes with selective samples, namely graduate students of one's own university. After all, if cognitive processes are universal, each student should be as good a subject for their exploration as anybody else. The same holds for studies in psycholinguistics (cf. Harley, 2008), which were largely based on the assumption that language has no effect on cognition and hence were all too often content with the English language and its speakers. And again, if one adopts the Chomskyan idea of a universal grammar, English should be as good a testing bed for its exploration as any other language.

But how can we ascertain that these processes are indeed universal if we do not test for universality?

\section{CULTURAL VARIANCE AND CHALLENGES FOR RESEARCH}

Criticism in this regard is far from new, but has gained increasing attention in recent years. As Arnett (2008) complains, the studies reported in six leading APA journals from 2003 to 2007 were almost exclusively conducted not only by researchers from 
English speaking and European countries, but also with samples from these same countries. In this respect, researchers neglected roughly $95 \%$ of the world population, about which - from a psychological and cognitive science perspective - we know practically nothing (see also Henry, 2008). The heavily researched 5\%, on the other hand, belong to "The WEIRDest people in the world" (Henrich et al., 2010b) in a double sense: They are from "Western, Educated, Industrialized, Rich, and Democratic societies," and, in global comparison, they must be considered a psychological outlier. With numerous examples, ranging from visual perception through spatial cognition, ethnobiological concepts, and economic decision-making, to self-concept and various social phenomena, Henrich et al. (2010b) demonstrate that many of the effects previously assumed to be robust and universal occur only weakly or not at all when sampling beyond WEIRD people (similar observations hold for linguistic universals; cf., Evans and Levinson, 2009).

This is not to say that such universals do not exist. Given the current research practice, however, only few of the assumed universals can be regarded as sufficiently established. Exploring cognitive diversity thus remains a fundamental goal for all cognitive sciences, and has become one of the hot topics in the field (Cohen, 2001; Norenzayan and Heine, 2005; Lloyd, 2007; Gentner, 2010). Meanwhile, conclusive evidence for deep cultural impacts not only on cognition, but on the very architecture of the brain, is even provided by neuroscience (Ambady and Bharucha, 2009; Kitayama and Uskul, 2011), which of all disciplines, is the one that might have been associated the most with universal claims from the outset, as it is perceived by many non-experts as not only reducing cognition to algorithms but to the very hardware of the processor: the neurons (cf. Gardner, 1985). Yet, neuroscience increasingly provides evidence for the assumption that the brain is altered by learning and experience, which itself is organized by culture.

However, while cross-cultural research is indispensable for scrutinizing cognitive diversity, it is a delicate thing to do. Some of the subtle difficulties arise from what Medin et al. (2010) dub "home-field disadvantages." The first home-field disadvantage is a tendency to leave one of the cultures under comparison unmarked, thereby taking it as the standard from which others deviate; as one consequence of this, peculiarities of the unmarked culture fall prey to cultural blind spots. The second home-field disadvantage is a tendency to consider other cultures (and occasionally even whole hosts of cultures) as more homogeneous than one's own culture, and definitely as more homogeneous than they actually are. This becomes most obvious when all Native Americans are lumped together as "the Indians," or Chinese, Japanese, and South Koreans are referred to as "the East Asians." The third home-field disadvantage is an excessive trust in the equivalence of tasks across cultures. This raises at least two concerns: a concern with how these tasks are understood in different cultural contexts (e.g., Astuti and Bloch, 2010) and how the response scales have to be interpreted (e.g., Heine et al., 2002), and a concern with what the obtained data would be able to reveal. As most tasks are specifically tailored to bring about a specific effect in the culture for which they were developed, regression toward the mean demands that in other conditions - and this implies in other cultures - this effect will be less likely to show up with the same task (Medin et al., 2010).
The home-field disadvantages result from presumptions that researchers hold about their field and the rules of the game. Such presumptions are nurtured by several handicaps, which increase psychological distance between the researchers and those they are researching (Trope and Liberman, 2003), and thereby hamper perspective taking (Galinsky et al., 2006). While the handicaps themselves cannot be circumvented, the disadvantages can be controlled. However, this requires constant efforts in marking the unmarked cultural group, collaborating with the group researched, conducting research on the terms of the respective culture, and taking multiple perspectives (Medin et al., 2010). It is exactly here, in the efforts to combat the home-field disadvantages, where cross-cultural research in cognitive science could profit most from taking an anthropological perspective.

\section{THE GIFT OF ANTHROPOLOGY: TAKING MULTIPLE PERSPECTIVES}

For almost a century now, anthropology has been cultivating the ideal of perspective taking. The conditio sine qua non of being a good anthropologist is not to take one's own culture as starting point. Instead, the ultimate goal, as Malinowski (1922) once put it, is “to grasp the native's point of view, his relation to life, to realize his vision of his world" (p. 25; and see Geertz, 1974; Bloch, 1998). To put it more technically: Anthropologists prefer an emic analysis, based on the categories from inside the system, over the etic analysis (Pike, 1967; and see Headland et al., 1990; Berry, 1999).

Anthropology, however, once a pioneer discipline and a founding member of the cognitive sciences (Gardner, 1985; D'Andrade, 1995), has increasingly withdrawn from the mutual endeavor during the last decades and is meanwhile considered the "missing discipline" in cognitive science (Boden, 2006). Several reasons have been identified for this alienation, and diverging methodological preferences are among the most important (Bender et al., 2010b; Boster, 2011). Nevertheless, in addition to the distinct perspective just mentioned, there are at least three more reasons why anthropology would still - and indeed, more so than ever - be an invaluable partner for cognitive sciences, and why efforts to re-integrate the former into the latter need to be intensified.

First, as we have seen, the division of labor between the disciplines was never really conducive in the first place; separating cognitive processes and cultural content does not do justice to the topic. If we assume that cognitive processes are affected by content, information on cultural variation in content is important for a more comprehensive understanding of processing (for an example, see Atran and Medin, 2008). For a broad range of cultures, anthropologists have been collecting data on cognitive content that need to be considered.

In addition, anthropology brings to the table its expertise on culture in general as a heuristic concept. This entails not only a heightened awareness of home-field disadvantages and continuous efforts for overcoming them as outlined above (cf., Weller and Romney, 1988; Headland et al., 1990; Agar, 1996; Ross, 2004; Bernard, 2006), but also a broader perspective on what culture is in the first place. The increasing interest in cognitive science for culture's constitutive role in human cognition has spurred an increasing number of crosscultural and cross-linguistic studies. All too often, however, these studies tend to reduce culture to simple, dichotomous variables, 
such as individualism vs. collectivism (for overview and critical assessments, cf., Fiske, 2002; Oyserman et al., 2002). Still largely neglected are interactions between cognition and culture in the sense of a cognitive ecology (Cole, 1996; Shweder, 2007; Hutchins, 2010).

And finally, the diverging methodological approaches of the disciplines could provide valuable complements - provided that they manage to overcome the reservations they hold against each other's preferences. Despite the fact that cognitive science and anthropology share a common goal, they nevertheless take diverging perspectives, with regard to both focus and methods (for an extensive treatment, see Boster, 2011; Mishra and Dasen, 2007). Most cognitive sciences, and particularly so psychology, are primarily interested in how cognitive processes operate and how they are related to each other. This interest suggests an analytical focus on the individual. The preferred method is the experiment, as it allows potentially interfering factors to be eliminated to a large extent, thus enabling the "pure" process to be scrutinized, which is essential in order to uncover causal mechanisms of cognitive phenomena. Cognitive anthropology, on the other hand, is primarily interested in cultural meaning in a more holistic manner, thus focusing on how cultural knowledge of groups of persons is organized and described, transmitted and modified. As most anthropologists conceive of culture not only as the origin (Tomasello, 1999), but also as an integral part of cognition (D'Andrade, 1981; Hutchins, 1995; Shore, 1996), they embed systematic data collection in field studies with participant observation (Agar, 1996).

At first glance, these methodological approaches appear to be mutually exclusive. As Boster (2011) elegantly puts it, "cognitive psychologists examine trees and cognitive anthropologists contemplate forests." A more thorough examination, however, reveals that in taking different angles, they are indeed complementary. Used together, they compensate for each other's weaknesses with their distinct strengths, thus paving the way for synergies beyond what could be achieved by each discipline alone (Beller and Bender, 2010). In order to obtain a comprehensive understanding of human cognition (including its cultural constitution), combining these approaches will be inevitable. One critical prerequisite for making use of this complementarity, however, is knowledge of and respect for the methodological principles of the respective other discipline.

\section{THE CASE FOR COLLABORATION AND CASES OF GOOD PRACTICE}

Collaboration across disciplines is encumbered with a host of difficulties, including different backgrounds in terms of knowledge, distinct theoretical conceptualizations and vocabulary, diverging research paradigms and methodological approaches, and different practical habits. For instance, psychologists are used to conducting research in teams and to publishing their results jointly, whereas anthropologists typically work in "their field" all by themselves, which is then reflected in their publications. Establishing respective cooperation is hence no simple endeavor. And only if they mutually acknowledge and respect each other's research traditions will they be prepared to invest the required effort. Inducing researchers from different traditions to collaborate will require more than simply making an appeal to do so, and anybody with experience in interdisciplinary work will be well aware of the pitfalls. However, these difficulties do not justify refraining from collaboration.
According to our own experience, there is little that is so supportive of a constructive exchange across disciplines as the willingness to jointly address common research questions and goals. In the case of cognitive research, it should not be too difficult to accomplish this. One promising starting point might be to place onto the shared research agenda the very topics upon which the various disciplines appear to disagree: From a serious discussion of the conceptualization of culture and its implications, through methodological issues, to a critical examination of universals. Crucially, however, this endeavor should not be undertaken on an abstract level, but needs to be grounded in a concrete cognitive domain and coupled to precise questions (even if these questions may have to be rephrased in the course of collaboration). It will also require identifying the level at which each discipline will discuss the phenomenon under scrutiny, and again, the different disciplines can complement each other in this respect, with cognitive psychology contributing a perspective on individual processing and tendencies of populations, and anthropologists contributing a perspective on the content and context of cognition in interactions.

A few cases of good practice provide evidence that crossdisciplinary collaboration can not only work well, but may be prosperous in giving rise to new and innovative research. Among the most convincing examples are the work on ethnobiological and ecological cognition and behavior conducted by the team of Douglas Medin and Scott Atran at Northwestern University (e.g., Medin and Atran, 2004; Medin et al., 2006; Atran and Medin, 2008) and the work on interactions of language, culture and cognition in Stephen Levinson's research group at the Max Planck Institute for Psycholinguistics in Nijmegen (e.g., Majid et al., 2004, 2007; Enfield and Levinson, 2006; Haun et al., 2006). Other instances include research on numerical cognition (Wassmann and Dasen, 1994; Pica et al., 2004; Dehaene et al., 2006, 2008; Beller and Bender, 2008), on causal and temporal reasoning (Beller et al., 2009; Bender et al., 2010a), on the cognitive foundations of religion and concepts of an afterlife (Bloch et al., 2001; Astuti et al., 2004; Whitehouse and McCauley, 2005; Astuti and Harris, 2008), on theory of mind (Wassmann et al., 2010), and on decision-making and rules of fairness in social dilemma situations (Henrich et al., 2005, 2010a).

Institutional attempts to support cross-disciplinary collaboration include the International Cognition and Culture Institute (ICCI), which provides a web-based platform for exchange, the Culture and the Mind project at the University of Sheffield, which investigates the cognitive and evolutionary foundations of culture and its impact on the mind, and the Center for Interdisciplinary Research (ZiF) of Bielefeld University, which provides funding for interdisciplinary residential groups. One of these groups (taking residence in 2011/2012) is specifically designed as a platform for re-integrating anthropology into the cognitive sciences and will focus on the cultural constitution of causal cognition.

These instances for communication and even cooperation between anthropology and the wider cognitive sciences are still the exception rather than the rule, and a lot of work remains to be done. Nevertheless, the potential for synergistic effects is remarkable, and the need for enhanced cross-disciplinary collaboration is increasingly acknowledged across disciplines. If cognitive science strives for a comprehensive understanding of human cognition, it needs to consider and integrate the perspective offered by anthropology on the cultural constitution of cognition. 


\section{REFERENCES}

Agar, M. H. (1996). The Professional Stranger. New York: Academic Press Inc.

Ambady, N., and Bharucha, J. (2009). Culture and the brain. Curr. Dir. Psychol. Sci. 18, 342-345.

Arnett, J. J. (2008). The neglected 95\%: why American psychology needs to become less American. Am. Psychol. 63, 602-614.

Astuti, R., and Bloch, M. (2010). Why a theory of human nature cannot be based on the distinction between universality and variability: lessons from anthropology. Behav. Brain Sci. $33,83-84$

Astuti, R., and Harris, P. L. (2008). Understanding mortality and the life of the ancestors in rural Madagascar. Cogn. Sci. 32, 713-740.

Astuti, R., Solomon, G. E. A., and Carey, S. (2004). Constraints on Conceptual Development: A Case Study of the Acquisition of Folkbiological And Folksociological Knowledge In Madagascar. Boston: Blackwell.

Atran, S., and Medin, D. L. (2008). The Native Mind and the Cultural Construction of Nature. Boston: MIT Press.

Baillargeon, R., Scott, R. M., and He, Z. (2010). False-belief understanding in infants. Trends Cogn. Sci. 14, 110-118.

Bang, M., Medin, D. L., and Atran, S. (2007). Cultural mosaics and mental models of nature. Proc. Natl. Acad. Sci. U.S.A. 104, 13868-13874.

Beller, S., and Bender, A. (2008). The limits of counting: numerical cognition between evolution and culture. Science 319, 213-215.

Beller, S., and Bender, A. (2010). Kognitionsethnologie und Kognitionspsychologie: Synergien nutzen. Zeitschrift für Ethnologie. 135, 233-248.

Beller, S., Bender, A., and Song, J. (2009). Weighing up physical causes: effects of culture, linguistic cues and content. $J$. Cogn. Cult. 9, 347-365.

Beller, S., and Spada, H. (2003). The logic of content effects in propositional reasoning: the case of 'conditional reasoning with a point of view'. Think. Reason. 9, 335-378.

Bender, A., Beller, S., and Bennardo, G. (2010a). Temporal frames of reference: conceptual analysis and empirical evidence from German, English, Mandarin Chinese, and Tongan. J. Cogn. Cult. 10, 283-307.

Bender, A., Hutchins, E., and Medin, D. L. (2010b). Anthropology in cognitive science. Top. Cogn. Sci. 2, 374-385.

Berlin, B. (1992). Ethnobiological Classification. Princeton, NJ: Princeton University Press.
Berlin, B., Breedlove, D. E., and Raven, P. H. (1968). Covert categories and folk taxonomies. Am. Anthropol. 70, 290-299.

Berlin, B., and Kay, P. (1969). Basic Color Terms. Berkeley: University of California Press.

Bernard, H. R. (2006). Research Methods in Cultural Anthropology, 4th Edn. Lanham: AltaMira.

Berry, J. W. (1999). Emics and etics: a symbiotic conception. Cult. Psychol. 5, 165-171.

Bloch, M. (1998). How We Think They Think. Oxford: Westview.

Bloch, M., Solomon, G. E. A., and Carey, S. (2001).Zafimaniry: an understanding of what is passed on from parents to children: a cross-cultural investigation. J. Cogn. Cult. 1, 43-68.

Block, N. (1995). "The mind as the software of the brain," in Thinking, Vol. 3, 2nd Edn, eds E. E. Smith and D. N. Osherson (Cambridge, MA: MIT Press), 377-425.

Boden, M. A. (2006). Mind as Machine Oxford: Clarendon Press.

Bond, C. F, and Titus, L. J. (1983). Social facilitation: a meta-analysis of 241 studies. Psychol. Bull. 94, 265-292.

Boster, J. S. (2011). "Data, method, and interpretation in cognitive anthropology," in The Blackwell Companion to Cognitive Anthropology, eds D. Kronenfeld, G. Bennardo, V. C. de Munck, and M. Fischer (Cambridge/ Oxford: Blackwell). 131-152.

Cohen, D. (2001). Cultural variation: considerations and implications. Psychol. Bull. 127, 451-471.

Cole, M. (1996). Cultural Psychology. Cambridge, MA: Harvard University Press.

D’Andrade, R. G. (1981). The cultural part of cognition. Cogn. Sci. 5, 179-195.

D'Andrade, R. G. (1995). The Development of Cognitive Anthropology. Cambridge: Cambridge University Press.

Dehaene, S., Izard, V., Pica, P., and Spelke, E. (2006). Core knowledge of geometry in an Amazonian indigene group. Science 311, 381-384.

Dehaene, S., Izard, V., Spelke, E., and Pica, P. (2008). Log or linear? Distinct intuitions of the number scale in Western and Amazonian indigene cultures. Science 320, 1217-1220.

Enfield, N. J. (ed.). (2004). Ethnosyntax: Explorations in grammar and Culture. Oxford: Oxford University Press.

Enfield, N. J., and Levinson, S. C. (eds) (2006). Roots of Human Sociality. Oxford: Berg.

Evans, J. S. B. T. (2003). In two minds: dual-process accounts of reasoning. Trends Cogn. Sci. 7, 454-459.

Evans, N., and Levinson, S. L. (2009). The myth of language universals: language diversity and its importance for cognitive science. Behav. Brain Sci. 32, 429-492.

Fiske, A. P. (2002). Using individualism and collectivism to compare cultures-A critique of the validity and measurement of the constructs: comment on Oyserman et al. (2002) Psychol. Bull. 128, 78-88.

Frake, C. O. (1964). Notes on queries in ethnography. Am. Anthropol. 89, 310-325.

Galinsky, A., Magee, J., Ena Inesi, M., and Gruenfeld, D. (2006). Power and perspectives not taken. Psychol. Sci. 17 1068-1074.

Gardner, H. (1985). The Mind's New Science. New York: Basic Books.

Geertz, C. (1974). “From the native's point of view": on the nature of anthropological understanding. Bull. Am. Acad. Arts Sci. 28, 26-45.

Gentner, D. (2010). Psychology in cognitive science: 1978-2038. Top. Cogn. Sci. 2, 328-344.

Goody, E. N. (1995). Social Intelligence and Interaction: Expressions and Implications of the Social Bias in Human Intelligence. Cambridge: Cambridge University Press.

Guerin, B. (1993). Social Facilitation. Cambridge: Cambridge University Press.

Harley, T. A. (2008). The Psychology of Language. Hove, NY: Psychology Press.

Haun, D. B. M., Rapold, C. J., Call, J. Janzen, G, and Levinson, S. C. (2006) Cognitive cladistics and cultural override in Hominid spatial cognition. Proc. Natl. Acad. Sci. U.S.A. 103 17568-17573.

Headland, T. N., Pike, K. L., and Harris, M. (eds). (1990). Emics and Etics. Thousand Oaks: Sage Publications.

Heine, S. J., Lehman, D. R., Peng, K., and Greenholtz, J. (2002). What's wrong with cross-cultural comparisons of subjective Likert scales? The referencegroup problem. J. Pers. Soc. Psychol. 82 903-918.

Henrich, J., Boyd, R., Bowles, S., Camerer C., Fehr, E., Gintis, H., McElreath, R. Alvard, M., Barr, A., Ensminger, J., Henrich, N. S., Hill, K., Gil-White, F. Gurven, M., Marlowe, F. M., Patton, J. Q., and Tracer, D. (2005). 'Economic man' in cross-cultural perspective: behavioral experiments in 15 smallscale societies. Behav. Brain Sci. 28 795-855.

Henrich, J., Ensminger, J., McElreath, R., Barr, A., Barrett, C., Bolyanatz, A., Cardenas, J. C., Gurven, M. Gwako, E., Henrich, N., Lesorogol, C., Marlowe, F., Tracer, D., and Ziker, J. (2010a). Markets, religion, community size, and the evolution of fairness and punishment. Science 327, 1480-1484.
Henrich, J., Heine, S. J., and Norenzayan A. (2010b). The weirdest people in the world? Behav. Brain Sci. 33, 61-135.

Henry, P. J. (2008). College sophomores in the laboratory redux: influences of a narrow data base on social psychology's view of the nature of prejudice. Psychol. Inq. 19, 49-71.

Hutchins, E. (1995). Cognition in the Wild. Cambridge, MA: MIT Press.

Hutchins, E. (2006). “The distributed cognition perspective on human interaction," in Roots of Human Sociality, eds N. Enfield and S. Levinson (New York: Berg), 375-398.

Hutchins, E. (2010). Cognitive ecology. Top. Cogn. Sci. 2, 705-715.

Kitayama, S. and Uskul, A. (2011). Culture, mind, and the brain: current evidence and future directions. Annu. Rev. Psychol. 62, 419-449.

Levinson, S. C. (2003). Space in Language and Cognition: Explorations in Cognitive Diversity. Cambridge: Cambridge University Press.

Levinson, S. C., and Wilkins, D. P. (eds). (2006). Grammars of Space: Explorations in Cognitive Diversity. Cambridge: Cambridge University Press.

Lévy-Bruhl, L. (1910). Les fonctions mentales dans les sociétés inférieurs. Paris: Felix Alcan.

Lévy-Bruhl, L. (1922). La mentalité primitive. Paris: Felix Alcan

Lloyd, G. E. R. (2007). Cognitive Variations. Oxford: Clarendon Press.

Lucy, J. A. (1992a). Grammatical Categories and Cognition: A Case Study of the Linguistic Relativity Hypothesis. Cambridge: Cambridge University Press.

Lucy, J. A. (1992b). Language Diversity and Thought: A Reformulation of the Linguistic Relativity Hypothesis. Cambridge: Cambridge University Press.

Majid, A., Bowerman, M., Kita, S., Haun, D. B. M., and Levinson, S. C. (2004). Can language restructure cognition? The case for space. Trends Cogn. Sci. 8, 108-114.

Majid,A., Bowerman, M., van Staden, M., and Boster, J. S. (2007). The semantic categories of cutting and breaking events: a crosslinguistic perspective. Cogn. Linguist. 18, 133-152.

Malinowski, B. (1922). Argonauts of the Western Pacific. London: Routledge and Kegan Paul.

Medin, D. L., and Atran, S. (2004). The native mind: biological categorization, reasoning and decision making in development across cultures. Psychol. Rev. 111, 960-983.

Medin, D.L., Bennis, W.M., and Chandler, M. (2010). Culture and the home-field disadvantage. Perspect. Psychol. Sci. 5, 708-713. 
Medin, D. L., Ross, N. O., and Cox, D. (2006). Culture and Resource Conflict. New York: Russell Sage Foundation.

Mehlhorn, K., and Sanders, P. (2008). Algorithms and Data Structures. Berlin: Springer.

Miller, G.A. (2003). The cognitive revolution: a historical perspective. Trends Cogn. Sci. 7, 141-144.

Mishra, R. D., and Dasen, P. R. (2007). "The methodological interface of psychology and anthropology," in Experiencing New Worlds, eds J. Wassmann and K. Stockhaus (New York: Berghahn Books), 21-35.

Nickerson, R. S. (1988). Counting, computing, and the representation of numbers. Hum. Factors 30, 181-199.

Nisbett, R. E. (2003). The Geography of Thought. New York: Free Press.

Nisbett, R. E., Peng, K., Choi, I., and Norenzayan, A. (2001). Culture and systems of thought: holistic versus analytic cognition. Psychol. Rev. 108, 291-310.

Norenzayan, A., and Heine, S. J. (2005). Psychological universals: what are they and how can we know? Psychol. Bull. 131, 763-784.
Norenzayan, A., Smith, E. E., Kim, B. J., and Nisbett, R. E. (2002). Cultural preferences for formal versus intuitive reasoning. Cogn. Sci. 26, 653-684.

Norman, D. A. (1993). Things That Make Us Smart. Reading, MA: Addison-Wesley.

Oyserman, D., Coon, H. M., and Kemmelmeier, M. (2002). Rethinking individualism and collectivism: evaluation of theoretical assumptions and meta-analysis. Psychol. Bull. 128, 3-72.

Pica, P., Lemer, C., Izard, V., and Dehaene, S. (2004). Exact and approximate arithmetic in an Amazonian indigene group. Science 306, 499-503.

Pike, K. L. (1967). Language in Relation to a Unified Theory of the Structure of Human Behavior. The Hague: Mouton.

Ross, N. (2004). Culture \& Cognition: Implications for Theory and Method. Thousand Oaks: Sage Publications.

Shore, B. (1996). Culture in Mind. New York: Oxford University Press.

Shweder, R. A. (2007). "An anthropological perspective: the revival of cultural psychology—some premonitions and reflections," in Handbook of Cultural
Psychology, eds S. Kitayama andD. Cohen (New York: Guilford Press), 821-836.

Sloman, S. A. (1996). The empirical case for two systems of reasoning. Psychol. Bull. 119, 3-22.

Sperber, D. (1997). Intuitive and reflective beliefs. Mind Lang. 12, 67-83.

Tomasello, M.(1999). The Cultural Origins of Human Cognition. Cambridge, MA: Harvard University Press.

Trope,Y., and Liberman, N. (2003). Temporal construal. Psychol. Rev. 110, 403-421.

Wassmann, J., and Dasen, P. R. (1994). Yupno number system and counting. J. Cross Cult. Psychol. 25, 78-94.

Wassmann, J., Träuble, B., and Funke, J. (eds). (2010). Theory of Mind:Reasoning Across Cultures. New York: Berghahn.

Weller, S. C., and Romney, A. K. (1988). Systematic Data Collection. Newbury Park: Sage.

White, P.A. (2006). The causal asymmetry. Psychol. Rev. 113, 132-147.

Whitehouse, H., and McCauley, R. N. (ed.). (2005). Mind and Religion. Walnut Creek, CA: Altamira.

Wu, S., and Keysar, B. (2007). The effect of culture on perspective taking. Psychol. Sci. 18, 600-606.
Zhang, J., and Norman, D. A. (1995). A representational analysis of numeration systems. Cognition 57, 271-295.

Conflict of Interest Statement: The author declares that the research was conducted in the absence of any commercial or financial relationships that could be construed as a potential conflict of interest.

Received: 19 November 2010; accepted: 29 March 2011; published online: 12 April 2011. Citation: Bender A and Beller S (2011) The cultural constitution of cognition: taking the anthropological perspective. Front. Psychology 2:67. doi: 10.3389/ fpsyg.2011.00067

This article was submitted to Frontiers in Cognitive Science, a specialty of Frontiers in Psychology.

Copyright (c) 2011 Bender and Beller. This is an open-access article subject to a nonexclusive license between the authors and Frontiers Media SA, which permits use, distribution and reproduction in other forums, provided the original authors and source are credited and other Frontiers conditions are complied with. 